$10 / 8.94950$

SANDIA REPORT

SAND93-2750 - UC-700

Unlimited Release

Printed January 1994

\title{
Optoelectronic Inventory System for Special Nuclear Material
}

F. H. Sieradzki

Prepared by

Sandla National Laboratories

Albuquerque, New Mexico 87185 and Livermore, Callfornia 94550

for the United States Department of Energy

under Contract DE-AC04-94AL8500D 
Issued by Sandia National Laboratories, operated for the United States Department of Energy by Sandia Corporation.

NOTICE: This report was prepared as an account of work sponsored by an agency of the United States Government. Neither the United States Government nor any agency thereof, nor any of their employees, nor any of their contractors, subcontractors, or their employees, makes any warranty, express or implied, or assumes any legal liability or responsibility for the accuracy, completeness, or usefulness of any information, apparatus, product, or process disclosed, or represents that its use would not infringe privately owned rights. Reference herein to any specific commercial product, process, or service by trade name, trademark, manufacturer, or otherwise, does not necessarily constitute or imply its endorsement, recommendation, or favoring vy the United States Government, any agency thereof or any of their contractors or subcontractors. The views and opinions expressed herein do not necessarily state or reflect those of the United States Government, any agency thereof or any of their contractors.

Printed in the United States of America. This report has been reproduced directly from the best available copy.

Available to DOE and DOE contractors from Office of Scientific and Technical Information PO Box 62

Oak Ridge, TN 37831

P:ices available from (615) 576-8401, FTS 626-8401

Available to the public from

National Technical Information Service

US Department of Commerce

5285 Port Royal Rd

Springfield, VA 22161

NTIS price codes

Printed copy: A03

Microfiche copy: AO1 
SAND93-2750

Distribution

Unlimited Release

Category UC -700

Printed January 1994

\title{
Optoelectronic Inventory System for Special Nuclear Material
}

\author{
F. H. Sieradzki \\ Optoelectronics Characterization \\ and Sensor Development Department \\ Sandia National Laboratories \\ Albuquerque, NM 87185
}

\begin{abstract}
In support of the Department of Energy's Dismantlement Program, the Optoelectronics Characterization and Sensor Development Department 2231 at Sandia National Laboratories/New Mexico has developed an in situ nonintrusive Optoelectronic Inventory System (OIS) that has the potential for application wherever periodic inventory of selected material is desired. Using a network of fiber-optic links, the OIS retrieves and stores "inventory signatures" from data storage devices (which are permanently attached to material storage containers) while inherently providing electromagnetic pulse immunity and electrical noise isolation. Photovoltaic cells (located within the storage facility) convert laser diode optic power from a laser driver to electrical energy. When powered and triggered, the data storage devices sequentially output their digital "inventory signatures" through light-emitting diode/photo diode data links for retrieval and storage in a mobile data acquisition system. An item's exact location is determined through fiber-optic network and software design. The OIS provides an "on-demand" method for obtaining acceptable inventory reports while eliminating the necd for human presence inside the material storage facility. By using modularization and prefabricated construction with mature technologies and components, an OIS installation with virtually unlimited capacity can be tailored to the customer's requirements.

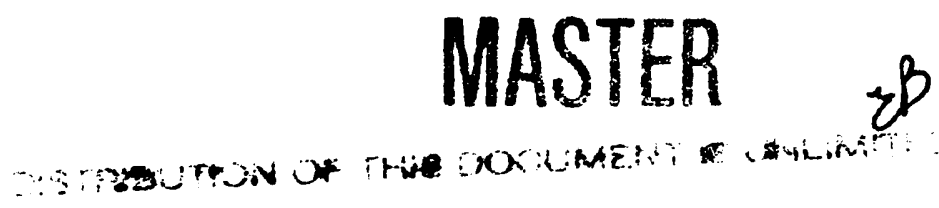




\section{Acknowledgments}

The author thanks the following Sandia personnel for their assistance in the design and development of the Optoelectronic Inventory System (OIS). C. C. Collins provided technical support in the selection of a fiber-optic switch for the data acquisition system. L. P. Schanwald and A $R$. Mahoney provided valuable information and technical support that lead to the incorporation of a segmented silicon cell for powering the pallet electronics. J. H. Perry provided digital circuit and software designs while M. R. Stegmaier designed circuit boards, fabricated prototypes, and performed digital system testing and analysis. K. R. Nielsen, with $R$. J. Sons and C. A Herr, not only conducted tests on the various system components anj subsystems, he also provided the author with guidance in the basics of optic and laser systems. C. A Herr deserves additional thanks for his patience and understanding in the face of numerous evictions from his laboratory while the OIS development team conducted laser tests and performed system demonstrations for potential customers. Finally, P. A. Longmire and B. C. Caskey are recognized for their support and funding of the OIS development program. 


\section{Contents}

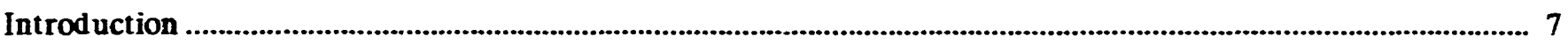

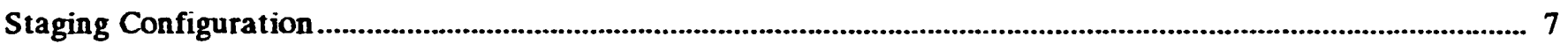

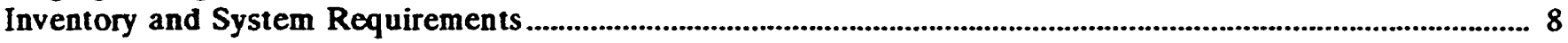

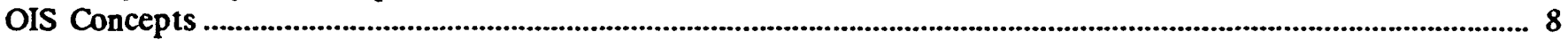

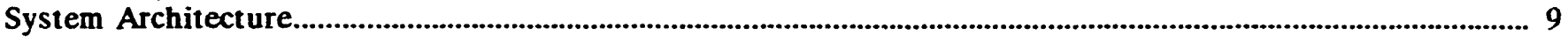

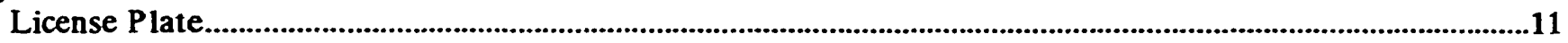

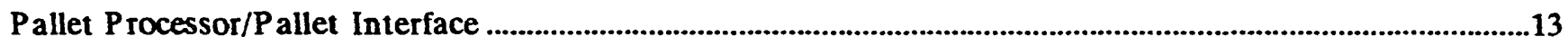

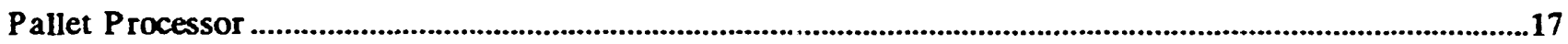

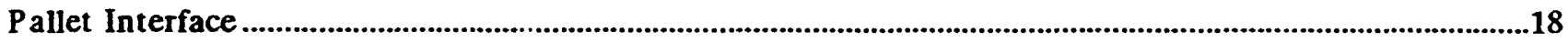

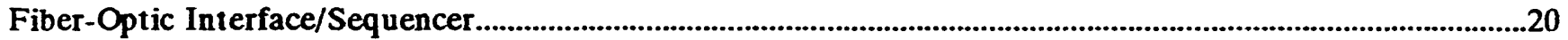

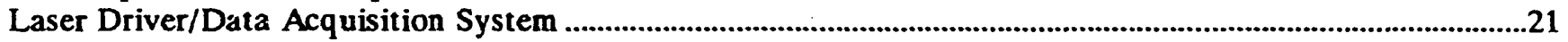

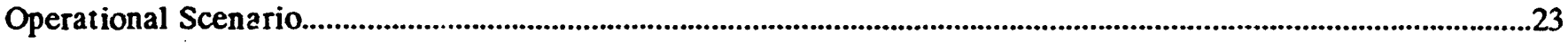

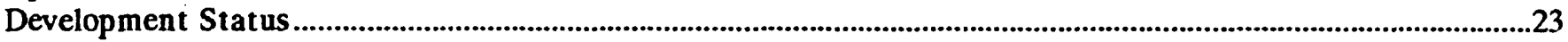

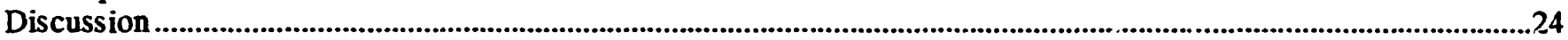

\section{Figures}

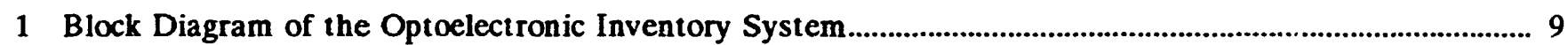

2 Artist's Concept of the Optoelectronic Inventory System ...........................................................................10

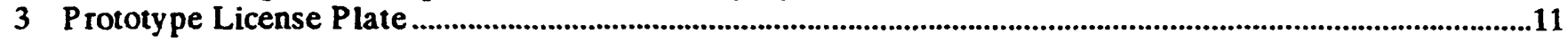

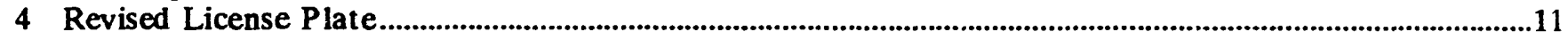

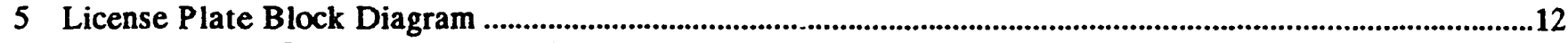

6 Demonstration Pallet Illustrating License Plate Size and Location ....................................................................13

7 PV Cell Illumination Concept for Proviaing Pallet Processor Power .............................................................14

8 Responsivity of a Solarex Cell as a Function of Wavelength ............................................................................15

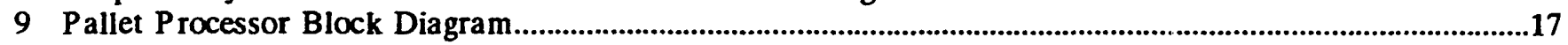

10 Pallet Processor Prototype and Installation in the Demonstration Pallet ........................................................18

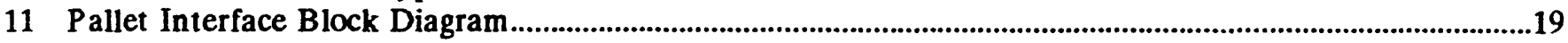

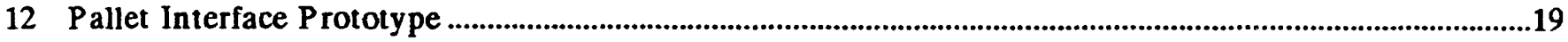

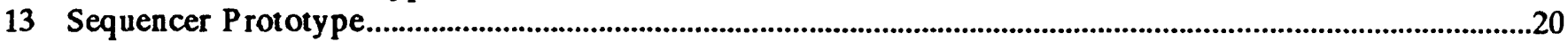

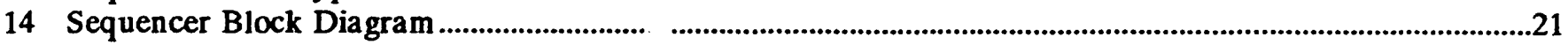

15 Prototy pe Laser Driver/Data Acquisition System ......................................................................................................22

16 Laser Driver/Data Acquisition System Block Diagram ...........................................................................................22

\section{Tables}

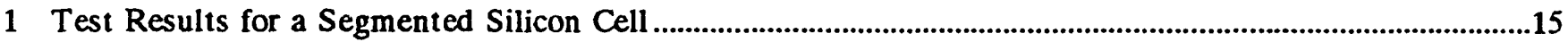

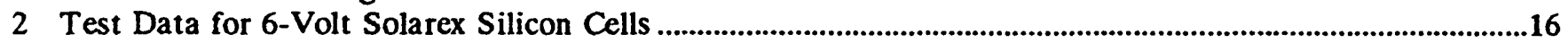

3 Calculated Beam Diameters for Selected Fiber NAs....................................................................................... 


\section{Executive Summary}

The scope of the nation's dismantlement program requires the staging (temporary storage) of large quantities of nuclear material (plutonium pits) in magazines at the Mason \& Hanger Pantex Plant. The proposed staging densities will result in elevated radiation levels inside the magazine thus making traditional methods of loading, inventorying, and ret rieving the items unacceptable. Therefore, Sandia's Dismantlement Program Management Department 5407 funded Project Stage Right to develop robotic systems capable of performing those tasks. Project Stage Right was structured with two phases. Phase one concentrated on developing an automated storage and retrieval system while phase two focused on maximizing staging density and development of enhanced methods to meet the periodic nuclear material accountability requirements of Department of Energy (DOE) Order 5633.3. In response to the need of phase two, the Optoelectronics Characterization and Sensor Development Department 2231 developed the Optoelectronic Inventory System (OIS) documented in this report.

With inventory operations, any system requiring magazine entry will be time consuming, labor intensive, and operationally costly. This is particularly true for the proposed aisle storage scenario, because all of the container pallets stored in the magazine aisle must be remojed for access to the remaining pallets. Obviously, an in situ nonintrusive system would demonstrate significant cost advantages when all of the site security and operational logistics are considered. Optoelectronic technology can provide those capabilities while meeting site safety and security requirements. The goal of the OIS program was to develop and demonst rate the capabilities of just such an optoelectronic system to Department 5407 and DOE before the end of April 1993.

Three major technical issues arose during the development program: (1) optical-to-electrical power conversion within the magazine, (2) providing an adequate level of optical energy for powering the large number of items stored in the magazine, and (3) our ability to accommodate the predicted pallet location: tolerances resulting from robotic forklift operations. Solutions to these issues led to an OIS system whose final configuration contains four major functionoriented elements: license plates (LP) for storing "inventory signatures," a pallet processor/pallet interface (PP/PI), a fiber-optic interface/sequencer (FOI/ Seq), and a laser driver/data acquisition system (LD/ DAS). The LP uses dual in-line package switches for storing the part and serial numbers of the plutonium pit and verifies the presence of the pit by measuring the temperature differential between the inside of the storage container and the surface of the LP. Using the principle of free space transmission of optical energy, the PP/PI concept can accommodate pallet misalignments of \pm 1.0 inch and bridge gaps up to 10 inches wide. Thus, no physical link is required to communicate with the electronics (PP) mounted on the storage pallet. The FOI provides fiber-optic connections to the outside of the magazine while the sequencer electronically selects the pallet to be inventoried and transmits the data to the LD/DAS through a light-emitting diode/photo diode fiber-optic data link. Finally, the LD/DAS controls system operation, supplies optic power, and receives, processes, and stores the inventory data.

Although the OIS, as documented in this report, is specific to the Pantex application, the concept is readily adaptable to other applications that require periodic inventory. Its potential for use in areas concerned with such items as precious metals, sensitive items, and hazardous materials is enhanced by its ability to incorporate various types of sensors and to adapt to a wide range of storage capacities. By using modularization and prefabricated construction with mature technologies and components, the OIS provides a faster, safer, and more cost-effective method of obtaining inventory data from a secured facility. 


\section{Optoelectronic Inventory System for Special Nuclear Material}

\section{Introduction}

Reductions in the United States nuclear stockpile will necessitate that the Department of Energy (DOE) stage (place in interim storage) the considerable quantity of nuclear material (plutonium pits) that will be recovered from weapons during the dismantlement process. Because the Rocky Flats pit staging facility is full, pits removed from retired weapons will be staged in Modified Richmond Magazines located in Zone 4 at the Mason \& Hanger Pantex Plant until permanent disposition is decided. Currently, each pit removed from a dismantled weapon is sealed in a 2030 version of the AL-R8 container. Each container has an identification label affixed to its side over which a plastic pocket is placed for insertion of an information tag. A second envelope is affixed to the cover or lid of the container. The containerized pits are then transported to the selected magazine for staging in an upright position on the floor of the magazine. Walkways are provided so that personnel have sufficient access to conduct periodic material accountability (inventory) operations.

To stage the large number of pits scheduled for recovery, a dramatic increase in the staging density would be mandatory; therefore, the DOE wanted to revise the Safety Analysis Report (SAR) so that the pit staging capacity could be increased by approximately 150 percent. Preliminary analysis indicated that the proposed staging densities would result in restrictive if not hazardous radiation levels with in the magazine. To minimize personnel exposure to radiation, automated systems would be developed to perform loading, ret rieval, and inventory operations. The urgency of the dismantlement program dictated that the development program be structured in two phases. Phase one would concentrate on developing the automated storage and retrieval system, and phase two would focus on maximizing staging density and developing enhanced methods for meeting the periodic nuclear inventory requirements. In response to a request for phase two proposais, the Optoelectronics Characterization and Sensor Development Department 2231 (formerly 2531) submitted a con- ceptual design on January 23, 1992, for an optoelectronic inventory system that has remained substantially unchanged throughout the development program. Those concepts included:

- Use of commercially available robust hardware

- Electronic tags to store an item's "inventory signature"

- Photovoltaic converters, located inside the magazine, to convert optical energy to electrical energy

- Laser diodes to power the photovoltaic converters by way of fiber-optic feedthroughs in the wall of the magazine

- Light-emitting diode (LED)/photo diode data links to transmit and receive inventory data through a fiber-optic cable

- A mobile tester to control system operation and data acquisition.

The proposed system will be capable of providing a complete inventory of the magazine without introducing power sources or requiring entry into the magazine. Additionally, the system would be selfprotecting in an electromagnetic pulse (EMP) environment.

\section{Staging Configuration}

Mason \& Hanger expects to have a minimum of 18 Modified Richmond Magazines available for pit staging. Each magazine has two chambers separated by a concrete wall. The approximate internal dimensions of each chamber are 40 feet long, 12 feet 6 inches wide, and 9 feet 6 inches high. The entire box-like structure is covered with several feet of earth overburden. The lone entrance to either chamber of the magazine is through steel-plate double doors approximately 8 feet 4 inches high by 10 feet 4 inches wide. An electrical system serves the magazine, but its use is restricted to security-rclated purposes. Natural ventilation of the structure is provided by a steel pipe in the ceiling of each chamber and small vents located at ground level on either side of the entrance. After 
the doors are sealed, large concrete obstructions deay access.

Although we considered numerous staging scenarios, the chosen scheme resulted in significant changes in the staging process while allowing staging flexibility. Because robotic systems would be used for loading and retrieving containers, operational access for the robot would eliminate a significant portion of the floor space for use as storage area. Only by stacking the containers in a two- or three-deep configuration could the required staging density be achieved. This staging configuration posed a problem for a robotcarried, machine-vision inventory system that requires line of sight with each container for serial number verification. By rotating the containers 90 degrees and staging them on their side, the containers could be stacked five high and provide access for the proposed instrumentation systems. The stacking would be accomplished by developing pallets to hold the containers. A 2-by-2 four-pack of containers would be placed on top of a 3-by-2 six-pack of containers. Eleven pallet stacks would be placed on each side of the access aisle in each bay for a capacity of 220 containers per bay or a total of 440 per magazine. Should this density prove insufficient to meet the overall staging capacity required, placing 12 additional pallet stacks in each aisle of the magazine would raise the total capacity per magazine to $\mathbf{6 8 0}$ units.

\section{Inventory and System Requirements}

Although Mason \& Hanger was pursuing various modifications to the pit accountability requirements of DOE Order 5633.3, the inventory requirements in effect at the start of this development effort were: (1) bi-weekly physical count verification, (2) monthly serial number verification, and (3) bi-monthly Category 1 inventory. The third requirement is an authentication of the nuclear material and must be performed regardless of the type of inventory system used. For the most part, other requirements resulting from Mason \& Hanger's operations were largely indeterminate, because their requirements were evolving as the robotic system's design and development proceeded. However, the following were established as baseline requirements:
- No power sources could be installed in the magazine, on the pallets, or on the containers.

- No antenna-like structure or conductive network could extend from the interior of the magazine to the exterior.

- Inventory data would consist of the 7-digit part number and 6-digit serial number of the pit.

- Predicted radiation level would be $100 \mathrm{mrem} /$ hr.

- Modifications to the magazine would be kept to a minimum.

Additionally, the following design guidelines were established by Department 2231 during development of the system:

- Robust, commercially available hardware with proven reliability would be incorporated to the maximum extent possible.

- To minimize system cost and increase reliability, no use-control devices or similar technology would be integrated into the system unless specifically requested.

- A 4-digit code for magazine and row identification would be incorporated in each sequencer.

- A 4-digit pallet identification code would be included in each pallet processor.

- A temperature differential measurement would be used to verify material presence.

\section{OIS Concepts}

The prototype Optoelectronic Inventory System (OIS) design is based on the concept that it is only one element in an integrated system of use control, site security, and material accountability. It is also founded on the belief that a credible and acceptable inventory report is achieved when total data compatibility is confirmed along with verification of the integrity of all site security and use-control systems. Therefore, for this application, we purposely limited the scope of the system to provide inventory signatures consisting only of part number and serial number while confirming material presence with a theimal monitor. By intentionally limiting the number of additional mechanisms or electronics, thereby keeping the design simple, we have a system whose costs are low and whose design is highly reliable. 


\section{System Architecture}

The OIS architecture, or structure, can best be described by discussing the system in terms of its four major functional areas:

- Data storage. The data storage function is performed by a "qicense plate" (LP) that uses dual in-line package (DIP) switches for storing a pit inventory signature. The inventory signature consists of the part and serial numbers of the pit. To verify the presence of the pit, the temperature differential between the inside of the container and the surface of the LP is measured.

- Pow er and data transmission. This function is accomplished in two ways. Standard electrical and optical interconnection techniques are used in all areas except for communicating with the storage pallets. To communirate with the pallet, we developed the pallet processor/ pallet interface (PP/PI) concept. Using the principle of free-space transmission of optical energy, the PP/PI link can accommodate pallet misalignment of $\pm \mathbf{1 . 0}$ inch and bridge gaps up to 10 inches wide. Thus, no physical connection is required to communicate with the electronics (LPs and PP) mounted on the stcrage pallet.

- Energy introduction and conversion within the magazine. The fiber-optic interface/sequencer (FOI/Seq) provides fiberoptic connections to the outside of the magazine, performs conversion of optic energy to electrical energy, electronically selects the pallet to be inventoried, and transmits the data to the exterior of the magazine through an LED/ photo diode fiber-optic data link.

- System control and data acquisition. Finally, a mobile laser driver/data acquisition system (LD/DAS) controls system operation, supplies optic power, and receives, processes, and stores the retrieved inventory data. A block diagram of the system is illustrated in Figure 1, and an artist's concept of the system is shown in Figure 2.

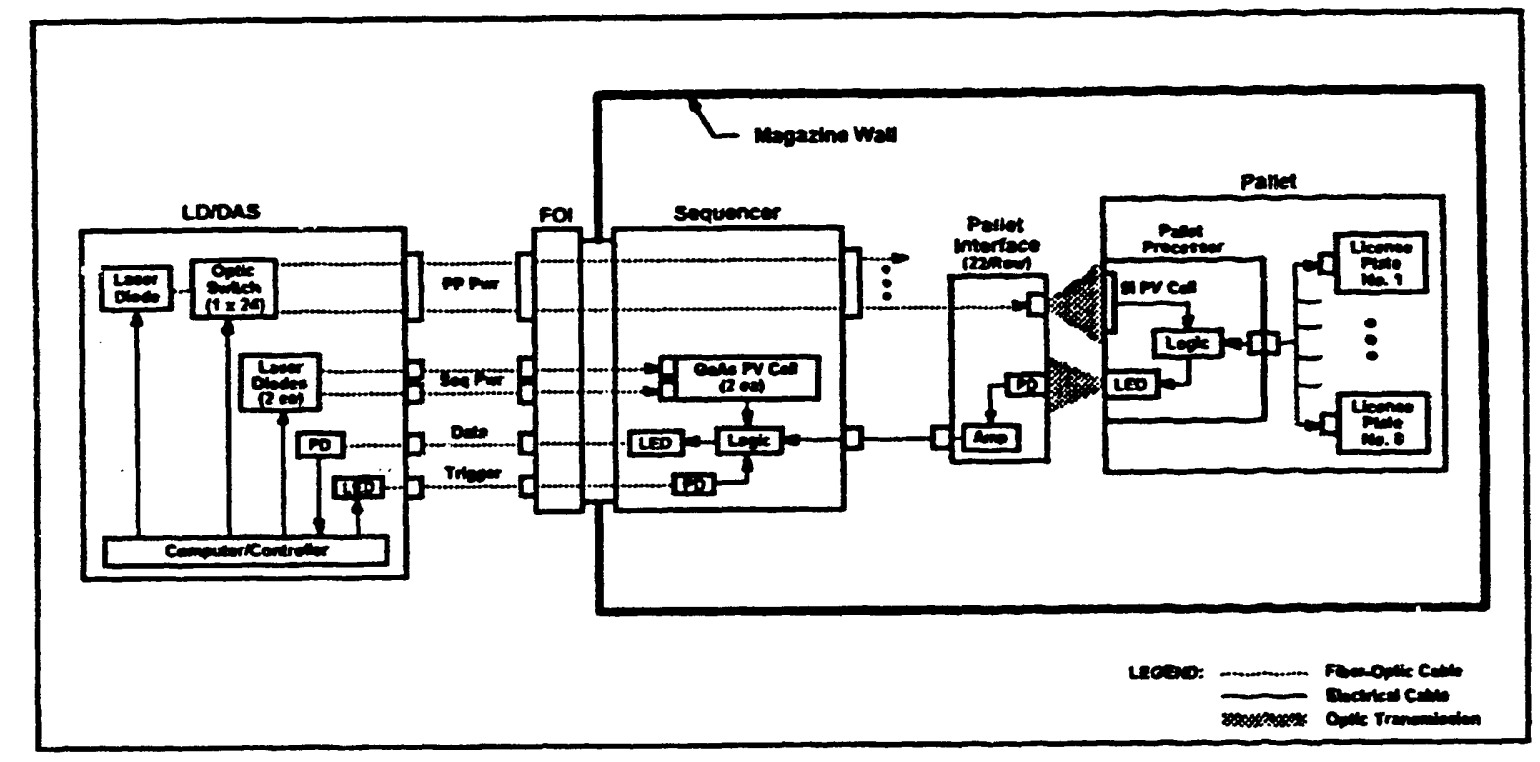

Figure 1. Block Diagram of the Optoelectronic Inventory System. 


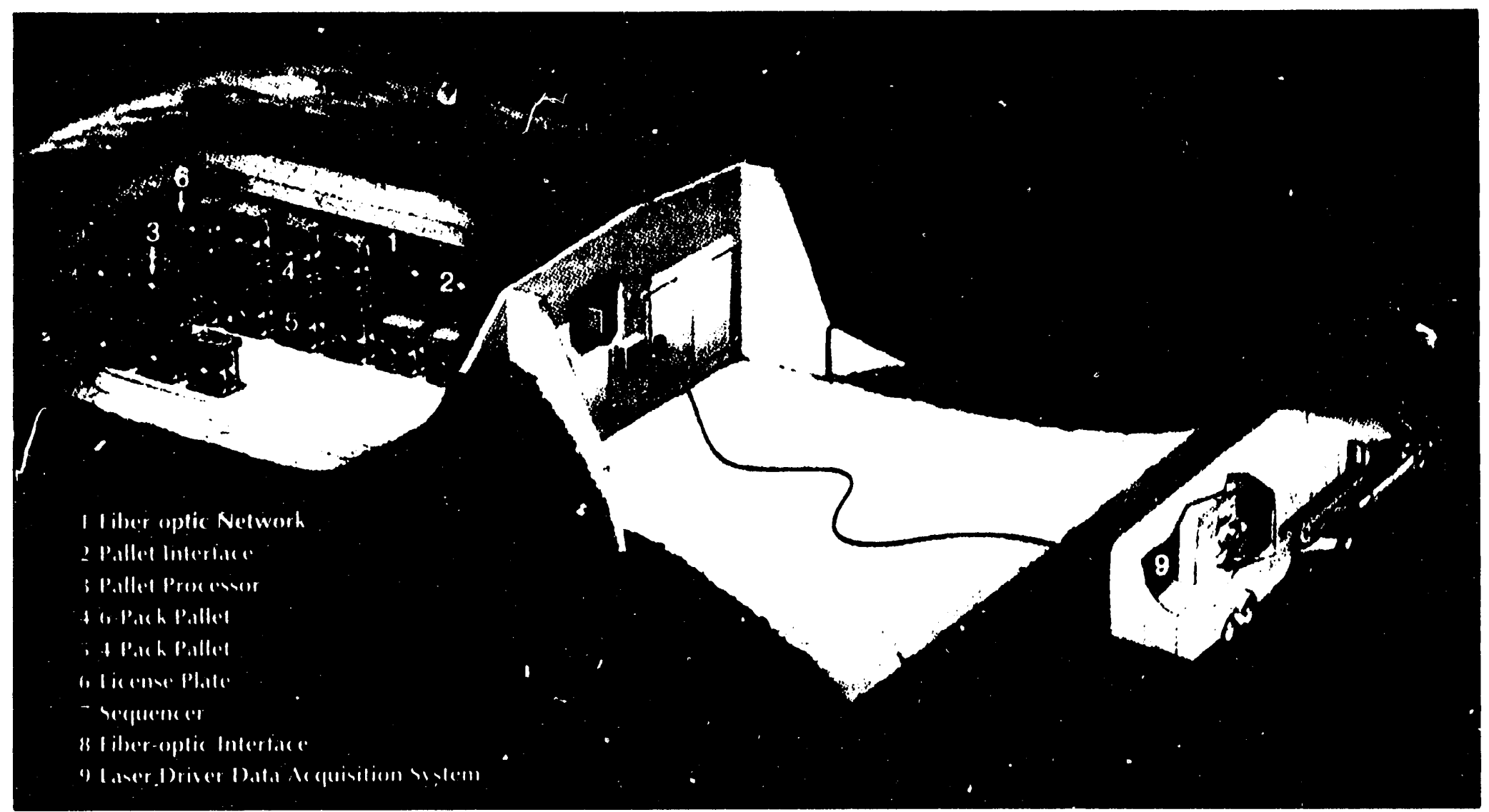

Figure 2. Artist's Concept of the Optoelectronic Inventory System (developed for use at the Mason \& Hanger Pantex Plant). 


\section{License Plate}

As previously stated, the LP stores data specific to each individual pit staged in the magazine; therefore, an LP is required for each container. Our initial LP prototype, shown in Figure 3, contained only a 10-digit identification number and was fabricated using DIP-style components and a JT-style interface connector. Although adequate for proving systcm concepts, this construction resulted in an LP whose size, 6.75 long by 3.25 wide by 1.25 high (inches) was impractical for its intended use. After the inventory data requirement was finalized as consisting of a seven-digit part number and a six-digit serial number, we rodesigned the LP using surface mount components and an MDM-style electrical connector. Although wi. added temperature probes and associated clectronics, the redesigned LP shown in Figure 4 was packaged in a modified Hoffman electrical enclosure whose final size was approximately 5.5 long by 2.5 wide by 1.0 high (inches). Five LPs were fabricated so that a full 4-pack pallet could be demonstrated and evaluated.

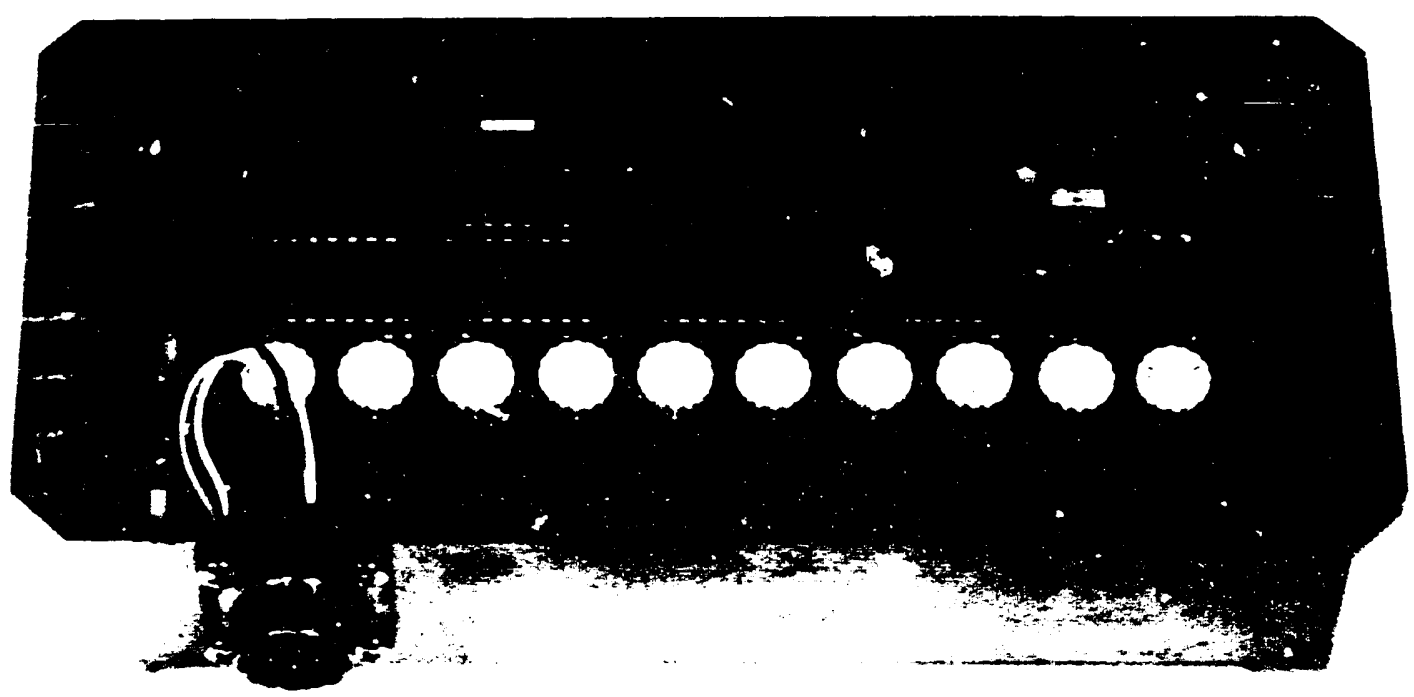

Figure 3. Prototype License Platc (initial design).

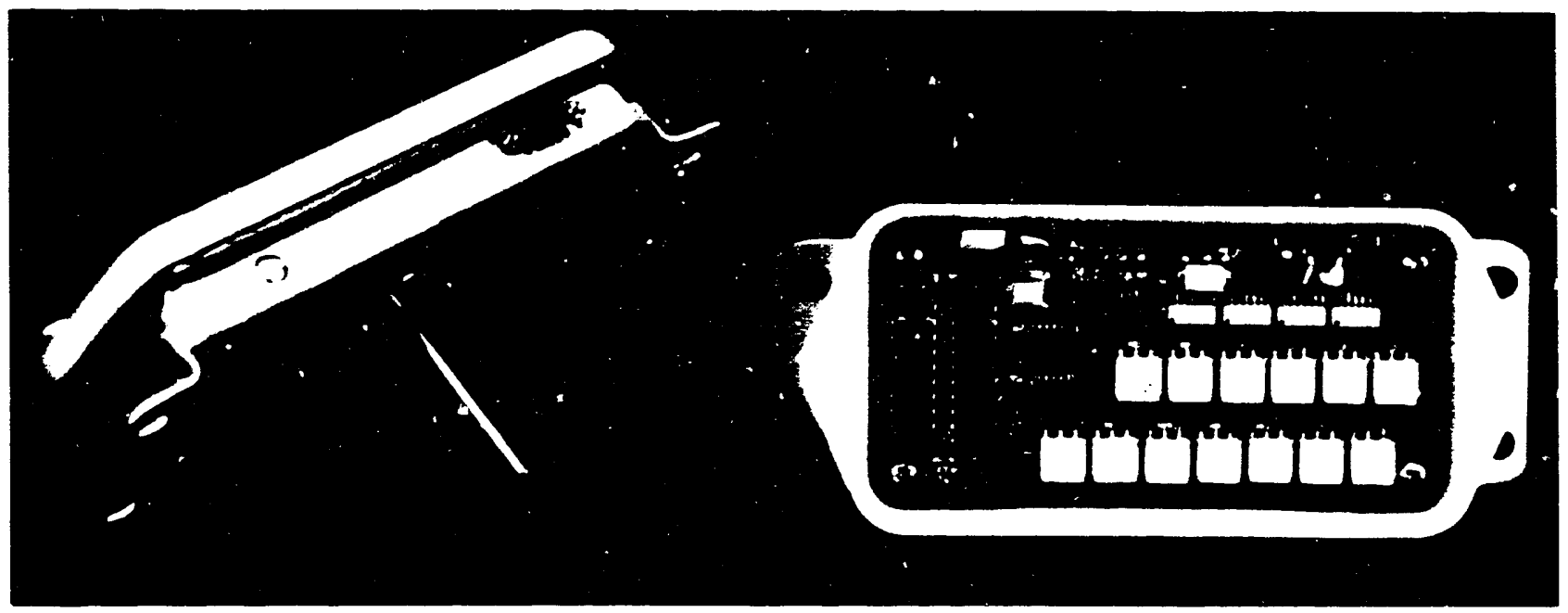

Figure 4. Revised License Platc (showing surface mount construction and thermistors). 
The OIS LP functions in the following manner. The part and serial numbers are stored in 13 binarycoded switches. Each switch encodes a single digit as a 4-bit binary number. Temperature information is obtained from two thermistors; one projects into the interior of the contaizer so that it is in close proximity to the pit and the second is mounted on the inside of the LP housing. Analog-10-digital (A/D) converters process the analog information from each thermistor, producing two 8-bit binary numbers. The outputs of the 13 switches and 2 AVD converters are tied to the parallel inputs of twelve 8-bit shift registers connected in series. Data is eventually transmitted to a computer for storage; start and stop bits are hardwired to establish RS232 format. A code number is hard-wired to allow software determination of data origin. (The LP data storage format is repeated in other OIS subsystems without temperature information). At power-up, a reset circuit inhibits control functions to allow the supply voltage to stabilize. After $100 \mathrm{~ms}$, a signal is sent to the AVDs, initiating conversion of two thermistor-derived, temperaturepruportional voltages to binary format. This information, along with the part and scrial numbers, is asynchronously loaded into the shift registers. The same signal used to start the conversion process also initiates a synchronization circuit. This circuit produces, on the second falling edge of an external clock signal, an output that enables the shift function of the shift regisiers. Because the shift function occurs on the rising edge of a clock, the synchronizer prevents simultaneous shift-enable and clock signals. The external clock driving the synchronizer is also input to the shift registers, causing the data previously loedeci to be shifted out serially for transmission to the PP. A block diagram of the LP is shown in Figure 5.

Installation of the LP during the staging process would likely occur in the following or similar scenario. An LP would be permanently attached to a container lid. When a pit is placed in the container, the switches of the LP would be programmed with the part and serial numbers of the pit. After the data is verified with a DAS, the LP and container would be sealed and the data reverified. The container would then be placed on a pallet. When the pallet is full, the LPs would be connected to a PP mounted on the pallet and the data would he verified again. Note that the unique design of the branched interconnecting cable would allow connection in only one manner, thus assuring correct location information for each container. Figure 6 shows the demonstration pallet with two containers instalked.

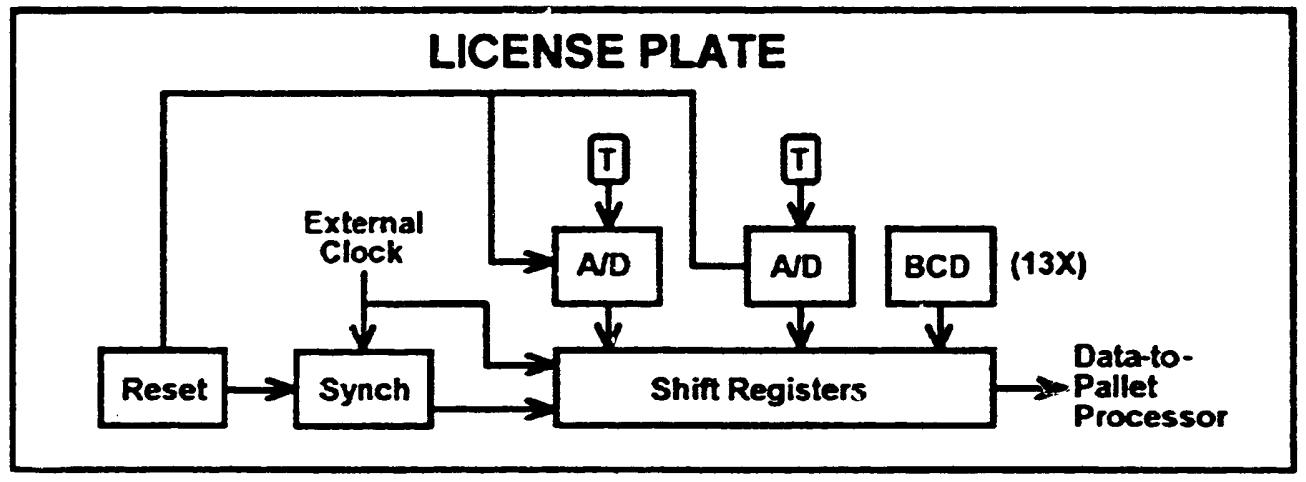

Figure 5. License Plate Block Diagram. 


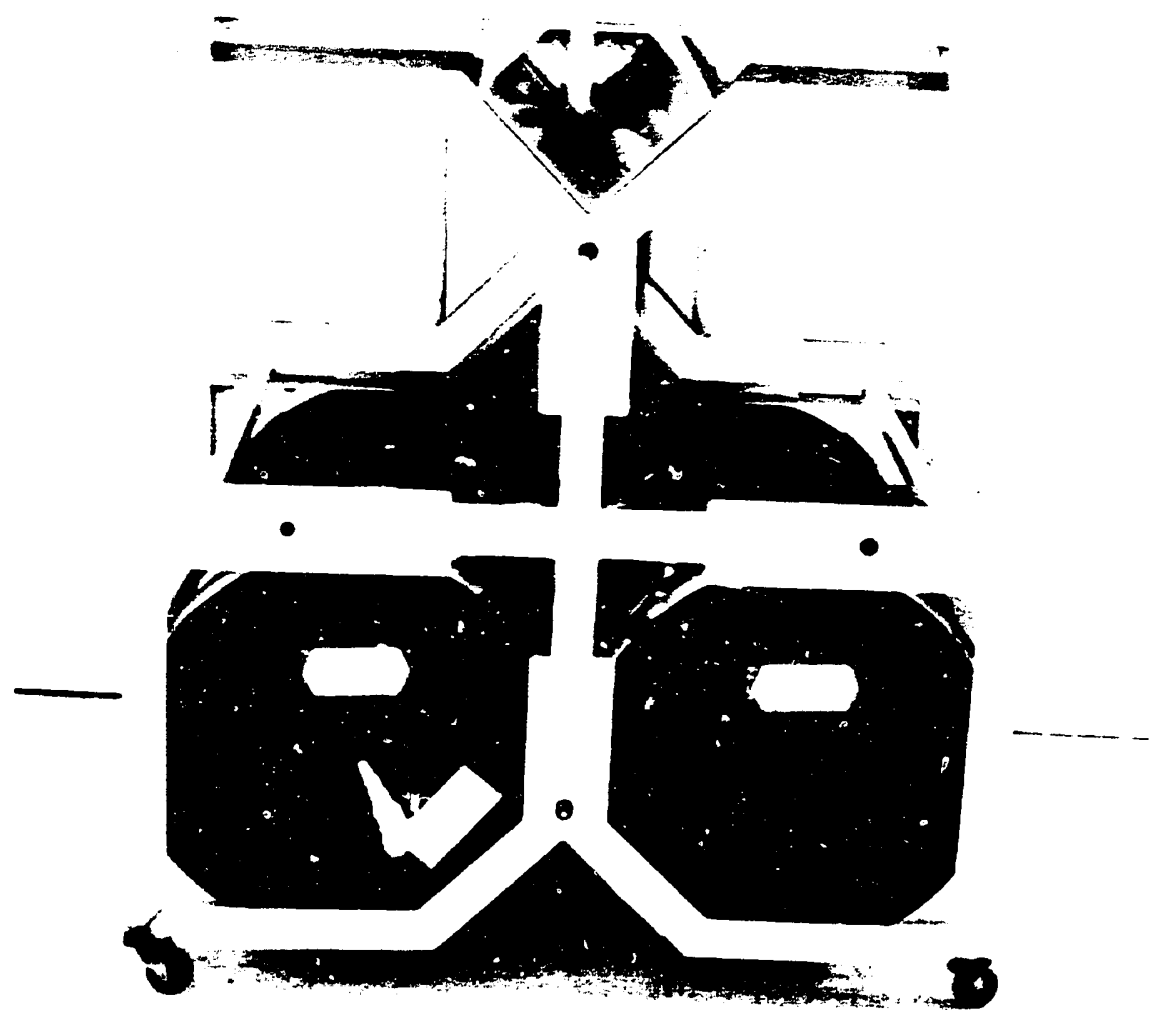

Figure 6. Demonstration Pallet Illustrating License Plate Size and Location.

\section{Pallet Processor/Pallet Interface}

Connecting to, powering, and receiving data from the pallet posed a significant problem. Initially, the pallet placement tolerance for the robotic staging system was expected to be no greater than \pm 0.25 inch; thus, the use of blind-mate connector techniques appeared to be the most cost-effective and robust method for communicating with the LPs. However, increased tolerance estimates rendered the blind mate approach unworkable. After evaluating various schemes, it was evident that optics posed the best method for completing this vital link. Attempts at providing a mechanical optical link proved just as futile as a mechanical electrical link. Only one other approach appeared feasible. We had to traverse the gap between the pallet and the magazine wall with a beam of laser-generated light large enough to accommodate the paiiet misalignment but with enough energy, when converted to electricity, to power an LP. Data could be returned in a similar fashion by using an LED/photo diode link. This scenario led to the development of the PP/PI concept.

A PP mounted on each pallet performs a number of functions:

- The PP receives laser light from the PI and converts it to electrical energy.

- The PP houses electronics for "talking to" the LPs mounted on the pallet.

- The PP houses LED electronics for sending data to the PI.

- For the demonstration unit, an optional 4-digit pallet identification circuit is included.

The? I provides a platform for directing the laser beam at the PP photovoltaic cell and houses a photo diode and amplifier circuit for receiving the data 
signals transmitted by the PP. A PI is mounted on the magazine wall at each nominal pallet location.

Getting laser light to the nominal location of any particular pallet is straight forward with the use of fiber-optic cables. Once at the $p_{-1}$ location, the optical energy must $b$. ... vited to electrical energy with a photovoltaic converter. Two types of converters offered the possibility of success: silicon cells or multijunction gallium-arsenide (GaAs) cells developed by Department 2231. The GaAs cell appeared the most likely candidate since it provides higher output voltages than silicon cells $(2,6,12$, or 16 volts versus $1 / 2$ volt). Since GaAs cells operate at high conversion efficiencies when properly illuminated, by using a 6 volt cell, sufficient voltage and current would be available for driving the P P and LP electronics. Illuminating the cell with sufficient photon energy was the key to its use.

The principle that a light beam diverges at a constant angle with increasing distance from its source could be used to accommodate the expected pallet positional tolerance. That is, the diameter of the beam at the target plane must be equal to or greater than the width of the tolerance zone plus the width of the PV cell being illuminated. As illustrated in Figure 7, the area of the tolerance zone would be approximately 150 times the area of the PV cell, resulting in less than 1 percent of the photon energy impacting the cell. Our laboratory tests confirmed the likelihood that this low level of efficiency would fail to produce the necessary electrical power.

Unless more photon energy could be focused on the cell, an extremely powerful and costly laser source would have to be used with resultant penalties in reliability, safety, and operational costs. Numerous attempts at focusing the beam on the cell with various types of fresnel, parabolic, and spherical lenses proved ineffective or unworkable. While compound lens arrangements and alignment schemes might work, it became obvions that system costs would escalate rapidly. The only alternative appeared to be silicon PV cells which, as shown in Figure 8, operate in a wide spectral bandwidth.

During discussions with the Photovoltaic System Components Department 6219 concerning cell selection, the idea of having a standard silicon cell segmented to give a 6-volt output surfaced. If enough current were available, voltage multiplier circuitry for supplying the voltage required for circuit operation would be unnecessary. We modified an on-hand cell to give a 5-volt output, and initial tests proved successful. Table 1 shows the cell output for various beam offsets and distances between the PV cell a. id the fiber end. Based on the test results, we identified potential suppliers and obtained sample cells from Solarex. The output range for the sample cells under conditions approaching optimum illumination with 1 watt of laser power is shown in Table 2.

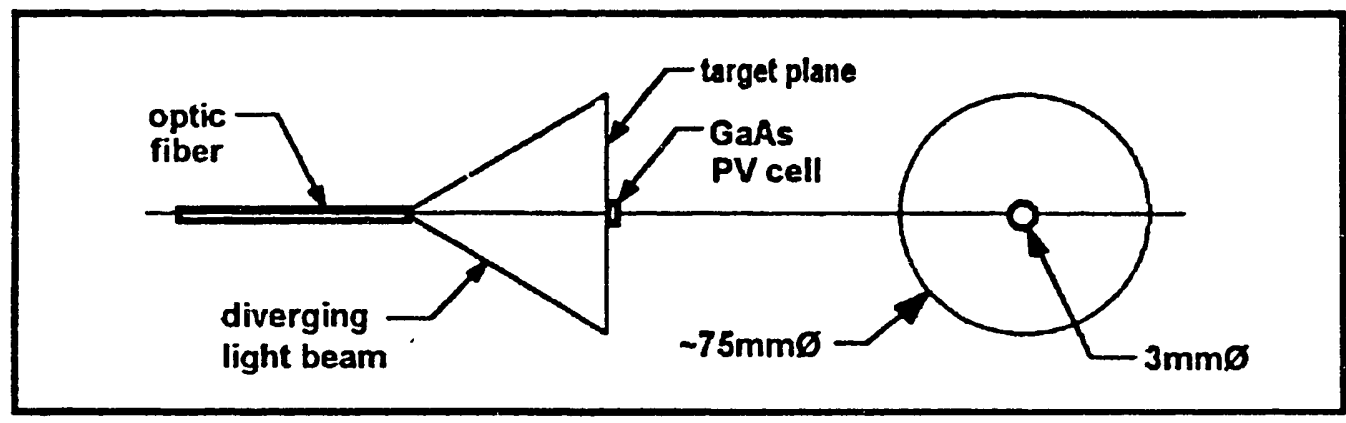

Figure 7. PV Cell Illumination Concept for Providing Pallet Processor Power. 


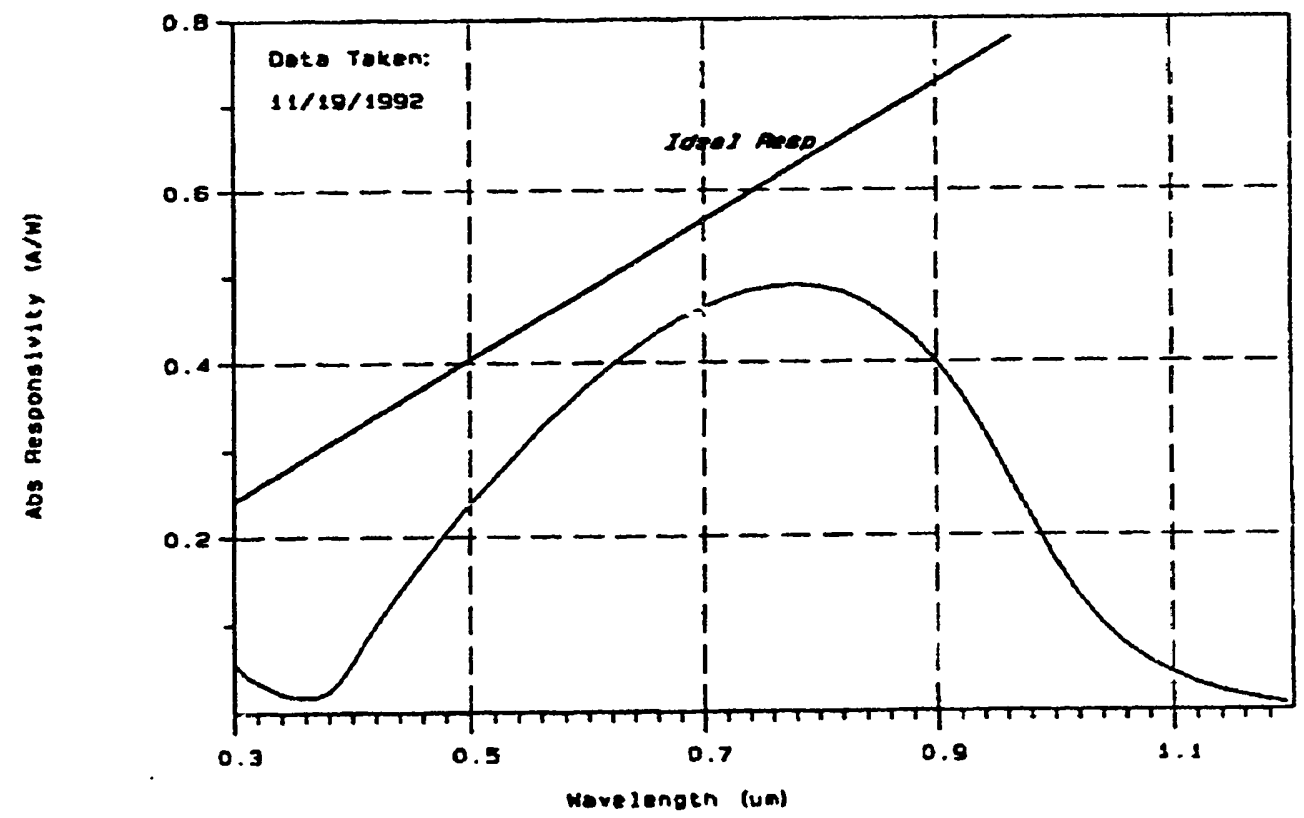

Figure 8. Responsivity of a Solarex Cell as a Function of Wavelength.

\section{Table 1. Test Results for a Segmented Silicon Cell (connected in series to produce a 5-volt nominal output).}

\begin{tabular}{|c|c|c|c|c|c|c|c|c|c|}
\hline \multirow[b]{2}{*}{$\begin{array}{l}\text { Laser } \\
\text { Power } \\
\end{array}$} & \multirow{2}{*}{$\begin{array}{c}\text { Distance } \\
\text { to Cell } \\
\text { (in.) }\end{array}$} & \multirow[b]{2}{*}{$\begin{array}{c}\text { Cell } \\
\text { Output }\end{array}$} & \multicolumn{7}{|c|}{ Lascr/Pv Cell Alignment } \\
\hline & & & $-1.5^{\circ}$ & $-1.0^{\circ}$ & $-0.5^{-}$ & $0.0^{\circ}$ & $+0.5^{-}$ & $+1.0^{\circ}$ & $+1.5^{\circ}$ \\
\hline \multirow{8}{*}{1 Watt } & \multirow{2}{*}{6} & Isc & & & & 10.59 & & & \\
\hline & & Voc & & & & 3.97 & & & \\
\hline & \multirow{2}{*}{8} & Isc & 13.91 & 16.57 & 17.43 & 17.67 & 17.30 & 16.04 & 13.89 \\
\hline & & Voc & 4.37 & 4.60 & 4.72 & 4.74 & 4.72 & 4.64 & 4.43 \\
\hline & \multirow{2}{*}{10} & Isc & 17.11 & 2.0 .38 & 2.30 & 22.96 & 21.90 & 18.90 & 15.78 \\
\hline & & Voc & 4.57 & 4.72 & 4.85 & 4.87 & 4.88 & 4.72 & 4.61 \\
\hline & \multirow{2}{*}{12} & Isc & 15.40 & 17.50 & 19.70 & 21.00 & 20.20 & 18.00 & 15.40 \\
\hline & & Voc & 4.46 & 4.56 & 4.68 & 4.81 & 4.75 & 4.63 & 4.49 \\
\hline \multirow{8}{*}{$1 / 2$ Watt } & \multirow[b]{2}{*}{6} & Iso & & & & 8.28 & & & \\
\hline & & Voc & & & & 3.50 & & & \\
\hline & \multirow[b]{2}{*}{8} & Isc & 8.58 & 10.29 & 11.35 & 11.49 & 11.20 & 10.16 & 8.39 \\
\hline & & Voc & 3.71 & 3.95 & 4.11 & 4.13 & 4.08 & 3.97 & 3.68 \\
\hline & \multirow{2}{*}{10} & Isc & 9.37 & 11.41 & 12.65 & 12.80 & 12.08 & 10.32 & 8.51 \\
\hline & & Voc & 3.92 & 4.15 & 4.32 & 4.30 & 4.24 & 4.04 & 3.79 \\
\hline & \multirow[b]{2}{*}{12} & Isc & 7.94 & 9.50 & 10.62 & 11.04 & 10.60 & 9.65 & 8.26 \\
\hline & & Voc & 3.67 & 3.89 & 4.06 & 4.09 & 4.00 & 3.94 & 3.75 \\
\hline
\end{tabular}


Table 2. Test Data for 6-Volt Solarex Silicon Cells.

\begin{tabular}{|c|c|c|}
\hline Cell No. & Isc (ma) & Voc (v) \\
\hline 5 & 15.2 & 5.75 \\
\hline 6 & 15.1 & 5.90 \\
\hline 8 & 12.5 & 5.80 \\
\hline 10 & 14.6 & 5.77 \\
\hline 11 & 13.0 & 6.03 \\
\hline 15 & 17.2 & 6.19 \\
\hline 17 & 14.6 & 6.15 \\
\hline 18 & 15.4 & 6.30 \\
\hline Avg. & 14.7 & 5.99 \\
\hline
\end{tabular}

Finally, it was necessary to select the fiber that would accommodate the expected range of pallet movement. Because the active area of the silicon cell is 5 inches wide and the positional tolerance of the pallet would be \pm 1.5 inches, the beam diameter at the plane of the PV cell had to be a minimum of 8 inches in diameter. In addition to this side-to-side tolerance, variations in the distance from the end of the fiber to the plane of the PV cell also had to be accommodated. Although the system can be designed to negate some of the tolerance, a gap width of 8 to 10 inches was used to determine the range of capability for the system. For optic fibers, the rate of divergence of a beam exiting the fiber is a function of the fiber's numerical aperture (NA), which is equal to the sine of the beam's conical half angle. Using the NA, the size of the beam at the plane of the PV cell can be calculated for various distances. Table 3 shows the calculated beam size at various distances for several numerical apertures. Based on these calculations, a rad hard fiber with an NA of 0.48 was selected for use in the PP/PI optic circuit.

Table 3. Calculated Beam Diameters for

Selected Fiber NAs (at various distances between the fiber end and the cell surface).

\begin{tabular}{|c|c|c|c|c|}
\hline \multirow{2}{*}{$\begin{array}{c}\text { Dis ta nce } \\
\text { to Cell }\end{array}$} & \multicolumn{4}{|c|}{ Numerical Aperture } \\
\cline { 2 - 5 } & $\mathbf{0 . 2 2}$ & $\mathbf{0 . 3 0}$ & $\mathbf{0 . 3 7}$ & $\mathbf{0 . 4 8}$ \\
\hline 5.00 & 2.26 & 3.14 & 3.98 & 5.47 \\
\hline 5.50 & 2.48 & 3.46 & 4.38 & 6.01 \\
\hline 6.00 & 2.71 & 3.77 & 4.78 & 6.57 \\
\hline 6.50 & 2.95 & 4.09 & 5.18 & 7.11 \\
\hline 7.00 & 3.16 & 4.40 & 5.58 & 7.66 \\
\hline 7.50 & 3.38 & 4.72 & 5.97 & 8.21 \\
\hline 8.00 & 3.60 & 5.03 & 6.37 & 8.75 \\
\hline 8.50 & 3.83 & 5.35 & 6.77 & 9.30 \\
\hline 9.00 & 4.06 & 5.66 & 7.17 & 9.85 \\
\hline 9.50 & 4.28 & 5.98 & 7.57 & 10.40 \\
\hline 10.00 & 4.51 & 6.29 & 7.97 & 10.94 \\
\hline 10.50 & 4.74 & 6.60 & 8.36 & 11.49 \\
\hline
\end{tabular}




\section{Pallet Processor}

The PP interrogates the LPs of a single pallet and transmits the data from as many as six LPs along with a PP 1aentification number. When optical power is applied to the PP photovoltaic cell, reset and synchronization circuitry similar to that of an LP enables a frequency divider. The divider produces, from an onboard programmable crystal oscillator, clock signals of $76.8 \mathrm{kHz}, 4.8 \mathrm{kHz}$, and $4.6875 \mathrm{~Hz}$. The $4.6875-\mathrm{Hz}$ clock signal drives a counter to generate a 3-bit count sequence on the address lines of a 1-to-8 decoder. One output line is addressed every clock cycle (0.2133s). The first addressed active output routes the $4.8-\mathrm{kHz}$ clock and a shift-enable signal to data storage circuitry containing a 4-digit PI number and hard-wired code, start, and stop bits. This data is shifted out to modulate the $76.8-\mathrm{kHz}$ clock. The modulated signal is then optically transmitted to the PI. Every 0.2133 second thereafter, power and the $4.8-\mathrm{kHz}$ clock is sent to a different LP; that data is then sent back to the PP modulation circuitry for optical transmission to the PI. The circuit design and interconnecting cable design predetermine the interrogation sequence so that exact item location car. be determined. A block diagram for the PP is shown Figure 9.

The PP is mounted in the base of the pallet at the intersection formed by four containers and is recessed to prevent damage during staging activities. For the demonstration unit, we used a standard Hoffman enclosure to house the electronics. Figure 10 shows the prototype P P and its installation in the pallet.

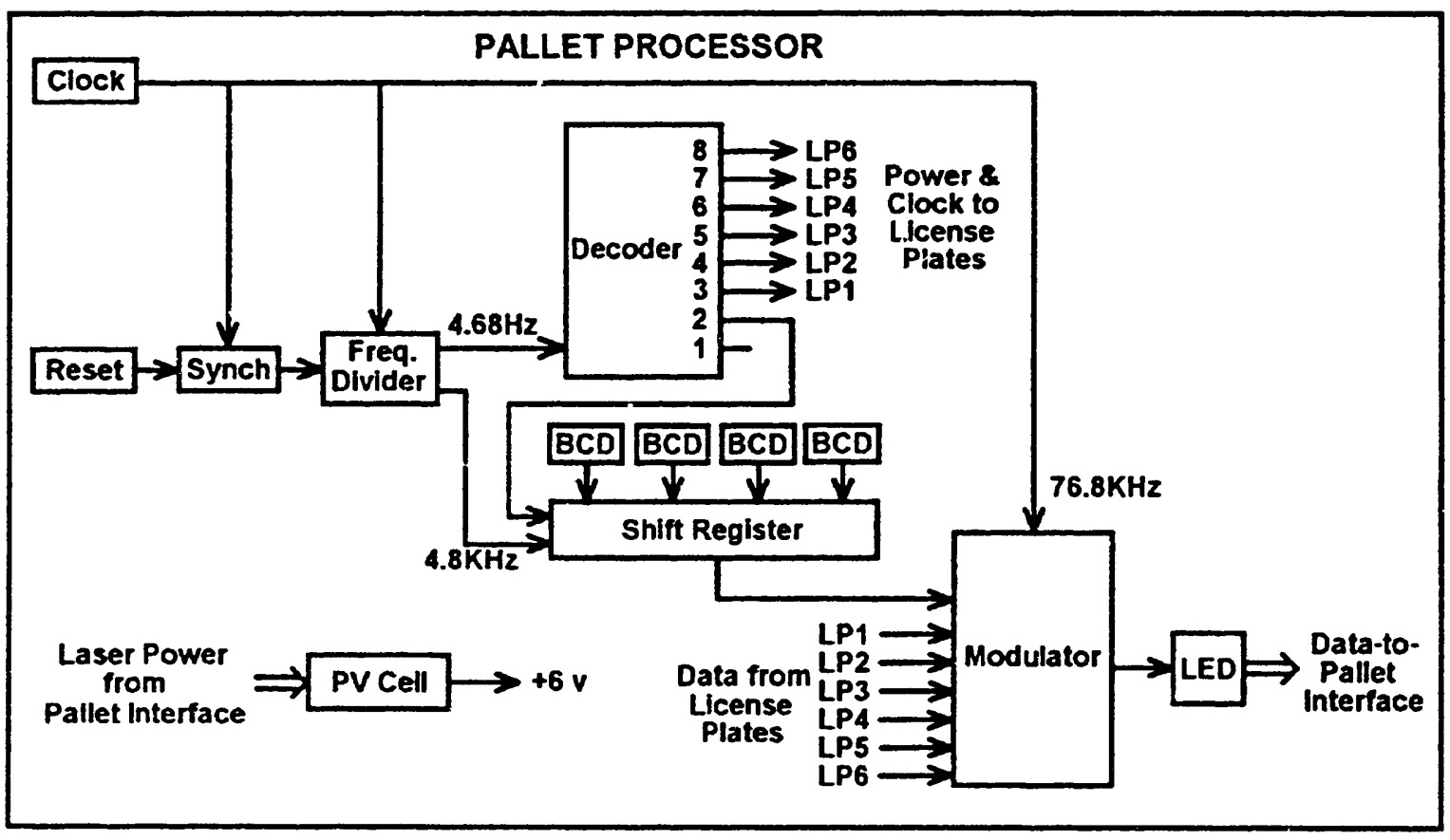

Figure 9. Pallet Processor Block Diagram. 

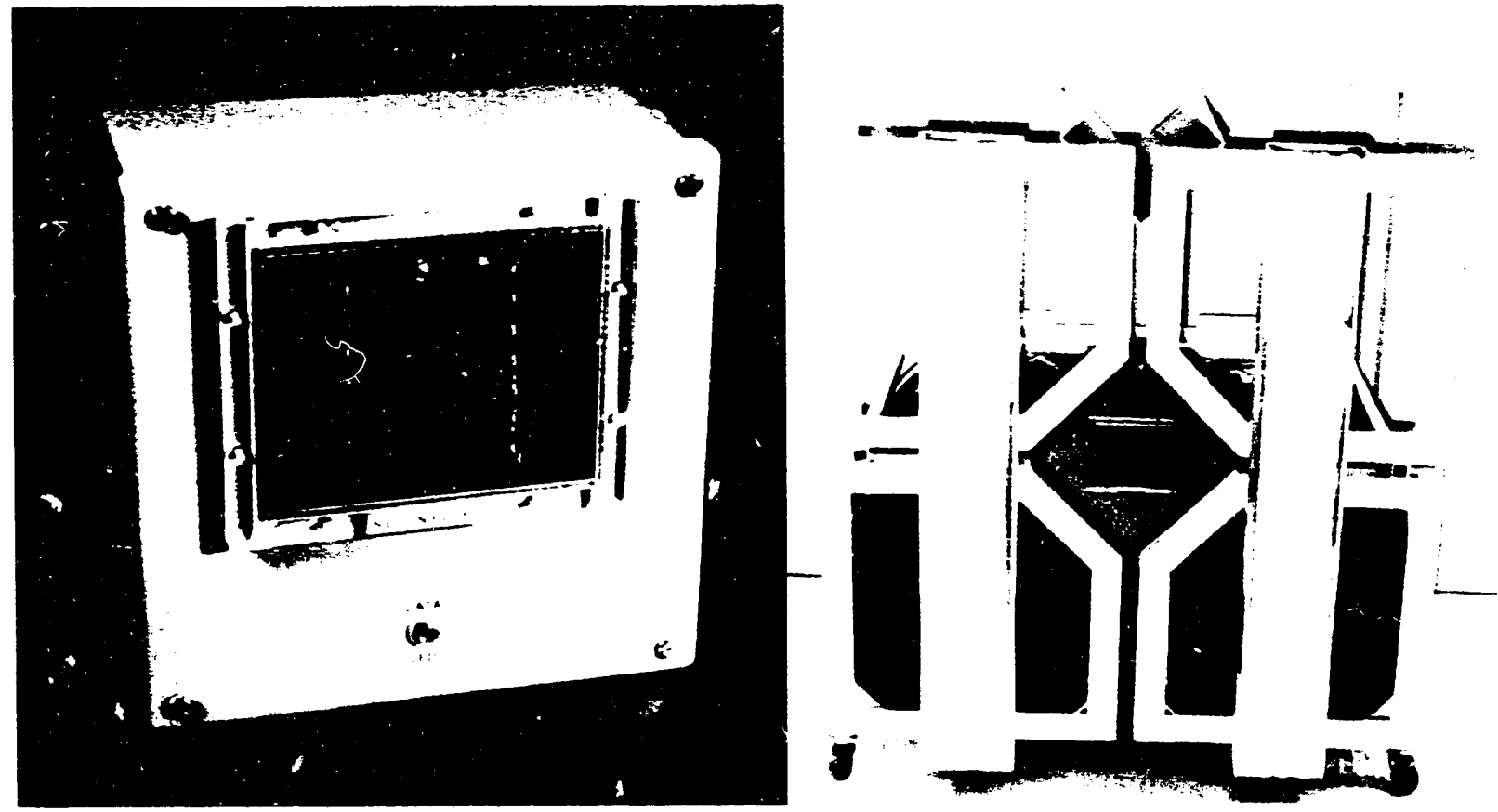

Figure 10. Pallet Processor Prototype and Installation in the Demonstration Pallet. (Note the change in cell alignment after installation on the pallet. The revised alignment accommodates a larger pallet locaticnal tolerance.)

\section{Pallet Interface}

The PI, whose block diagram is shown in Figure 11 , supplies optical power to drive the photovoltaic cell of the PP and to demodulate the subsequent optical data for electrical transmission to the next stage. A photo diode detects the optical signal from the PP, which is then amplified, demodulated, and buffered. Data is then electronically transmitted to the sequencer. To prevent the signal processing circuitry from producing power-on or power-off glitches aiong with valid data, an analog switch is placed in series with the processor output. The switch control circuitry prevents data output for $100 \mathrm{~ms}$ after powerup. Additionally, the output is disabled whenever the supply voltage is less than 2 volts above the minimum required for proper operation.

Like the PP, the prototype PI shown in Figure 12 is housed in a standard Hoffman enclosure. The PI is mounted on the wall of the magazine or supporting structure and connected to the FOI/Seq with prefabricated fiber-optic and electronic cable harnesses for laser power and data transmission, respectively. 


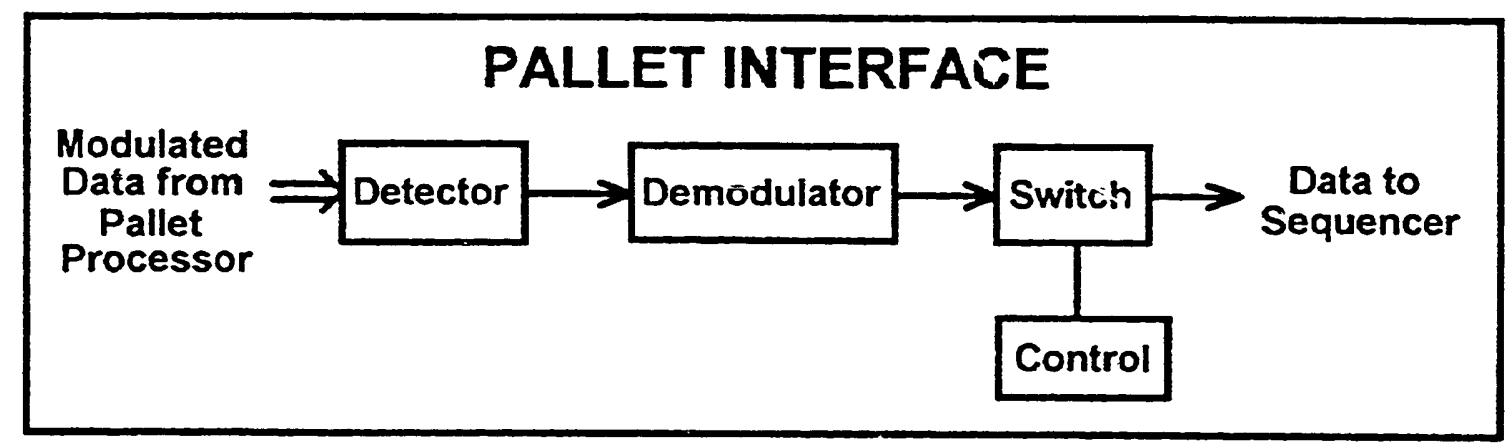

Figure 11. Pallet Interface Block Diagram.

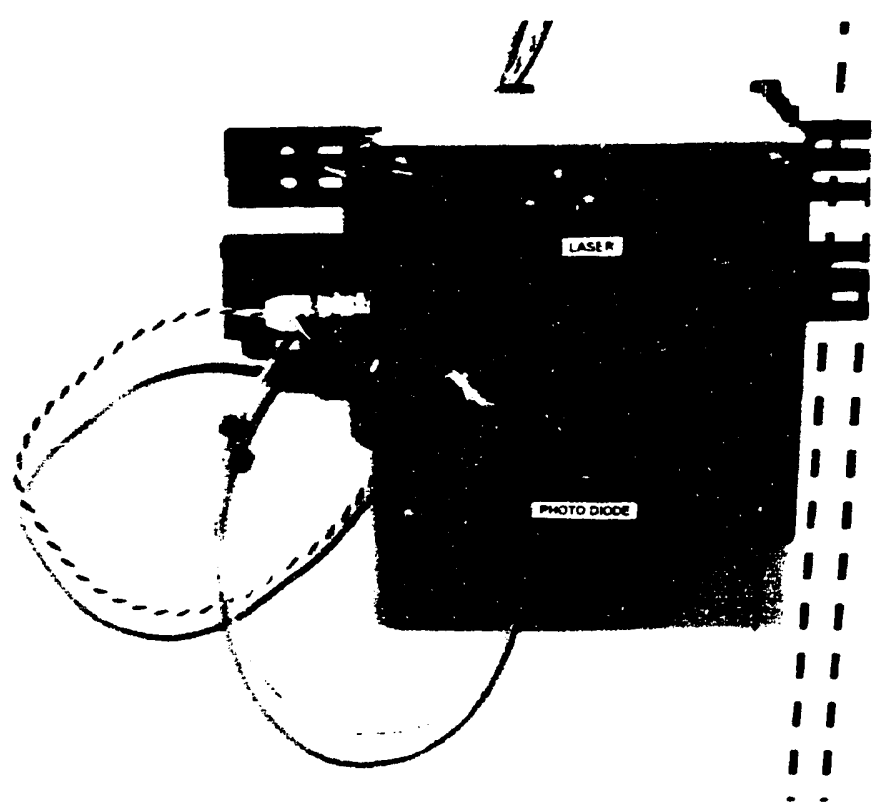

Figure 12. Pallet Interface Prototype. 


\section{Fiber-Optic Interface/Sequencer}

The FOI/Seq subsystem performs a number of functions. The FOI performs the same basic function as the electrical power panel does in commercial or residential establishments, except that in this case, the power being receivid is laser or LED-generated light. An interconnecting panel mounted on the cxterior wall of the magazine contains a series of fiberoptic connectors for making connections to the LD/ DAS. Within the interface, fiber-optic cables are fed to the interior of the magazine where some connect to PIs through fiber-optic harnesscs. Other fibers are used to provide power for the sequencer, which is located on the interior wall of the magazine. Inside the sequencer, laser light is converted to electrical encrgy by two 6-volt GaAs photovoltaic converters connected in series, thus providing 6- and 12-volt power for circuit operation.

For the Pantex magazines, one FOI/Seq would be installed in each bay of the magazine with each sequencer containing three channels for data acquisition: one channel per row of pallets and one for the aisle (if aisle storage is required). Each channel would receive data from as many as $24 \mathrm{PIs}$. For the demonstration unit, the prototype sequencer (shown in Figure 13) was constructed with only one channel.

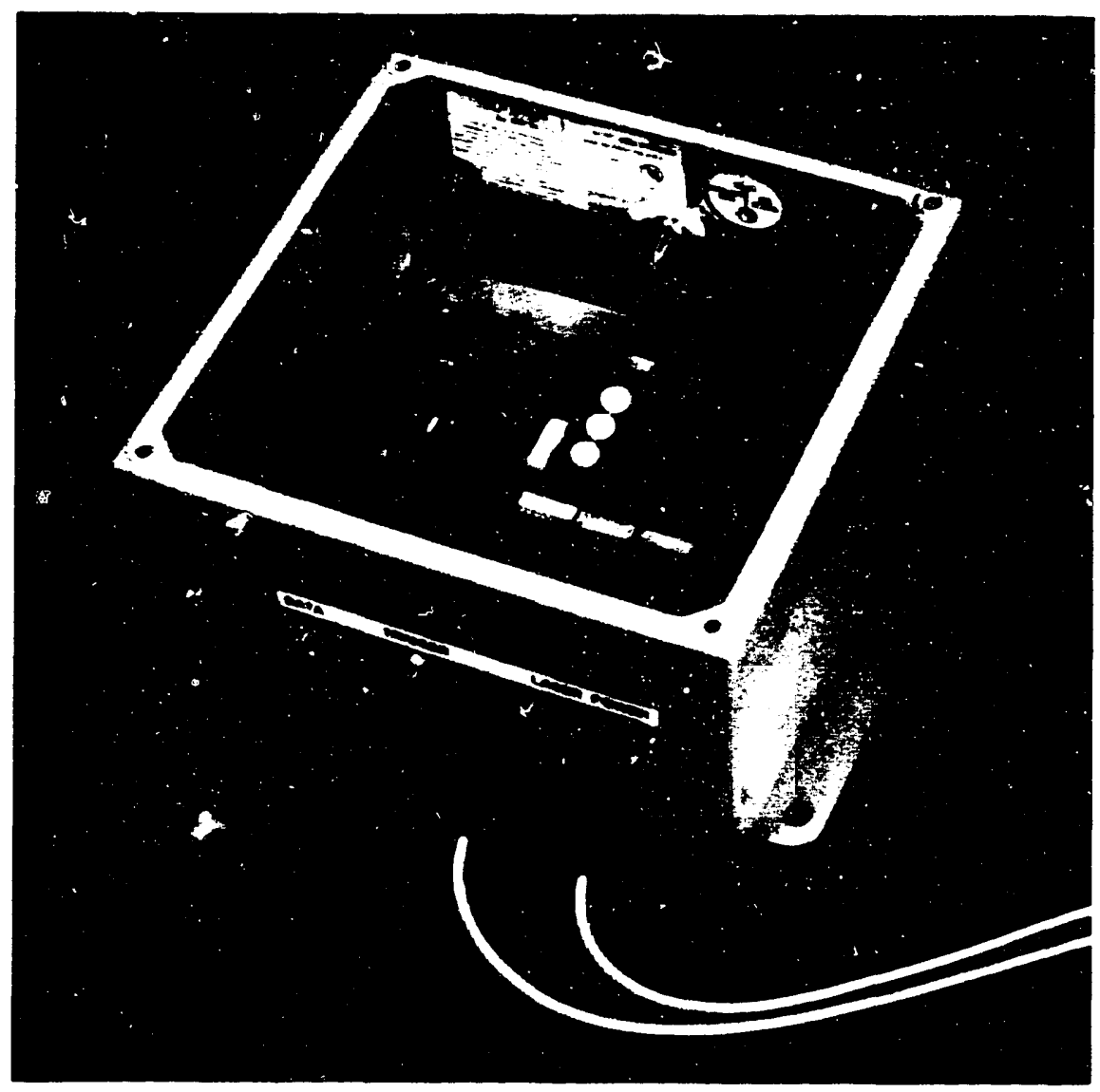

Figure 13. Scquencer Protolype. 
The sequencer collects data from 24 PPs through their PIs, outputting that data and a 3-digit sequencer identification number. A block diagram of the sequencer is shown in Figure 14. On power-up, reset circuitry inhibits sequencer function for $100 \mathrm{~ms}$, after which time an external cont rol pulse is necessary to start operation. The first pulse increments a counter driving a 1-of-26 decoder; the first line addressed in this manner causes an output to be produced from a synchronizer circuit. The synchronizer output acts as the shift-enable signal for data storage circuitry containing the 3-digit sequencer identification number. The sequencer also enables a frequency divider driven by an onboard programmable crystal oscillator, producing a $4.8-\mathrm{kHz}$ clock to shift this data out (along with the hard-wired code, start and stop bits). The next 24 external control pulses address the remaining 24 lines of the decoder in sequence; each line addressed causes power to be output to a different PI. The subsequent data transmissions back to the sequencer are diode-ored and optically transmitted to the LD/DAS preceded by the sequencer identification rumber.

\section{Laser Driver/Data Acquisition System}

The LD/DAS fabricated for the demonstration unit is shown in Figure 15. The laptop computer stores data a .1d controls the system while the chassis contains the optic power sources and system electronics. Optic power is provided by three 1-watt EnsignBickford laser diodes. Two lasers power the sequencer whil: the remaining laser sequentially provides power to the PIs in each row using a fiber-optic switch. Remaining circuitry includes laser drivers for powering the laser diodes, photo diode circuitry for receiving the LED signals from the sequencer, and sequencer-like circuitry for synchronizing the optic switch operation with the data-receiving circuitry.

The LD/DAS functions in the following manner. The sequencer-like circuit synchronizes the functions of the previously described subsystems, generating control signals to power the PPs and PIs. The LD/ DAS detects the data output of the sequencer for subsequent transmission to a computer for storage. On power-up, reset and synchronization circuitry enable a frequency divider (driven by a programmable crystal oscillator) to produce a $0.24-\mathrm{Hz}$ clock signal (1 pulse every 4.16 seconds). This signal serves as the external control pulse for the sequencer and drives a counter to increment an optical switch, controlling power to the PPs. In this manner synchronous power is applied to the PPs (optically through the switch) and the PIs (electrically through the sequencer). A second synchronization circuit (driven by the $0.24-\mathrm{Hz}$ clock) enables the counter driving the optical switch. Because the output toggles on the second falling clock edge, the optical switch is not incremented until the second clock pulse, allowing the sequencer identification number to be sent before the PP data. Optical data received from the sequencer is detected and coriverted to RS232 voltage levels for transmission to the computer for storage. A block diagram of the LD/DAS is shown in Figure 16.

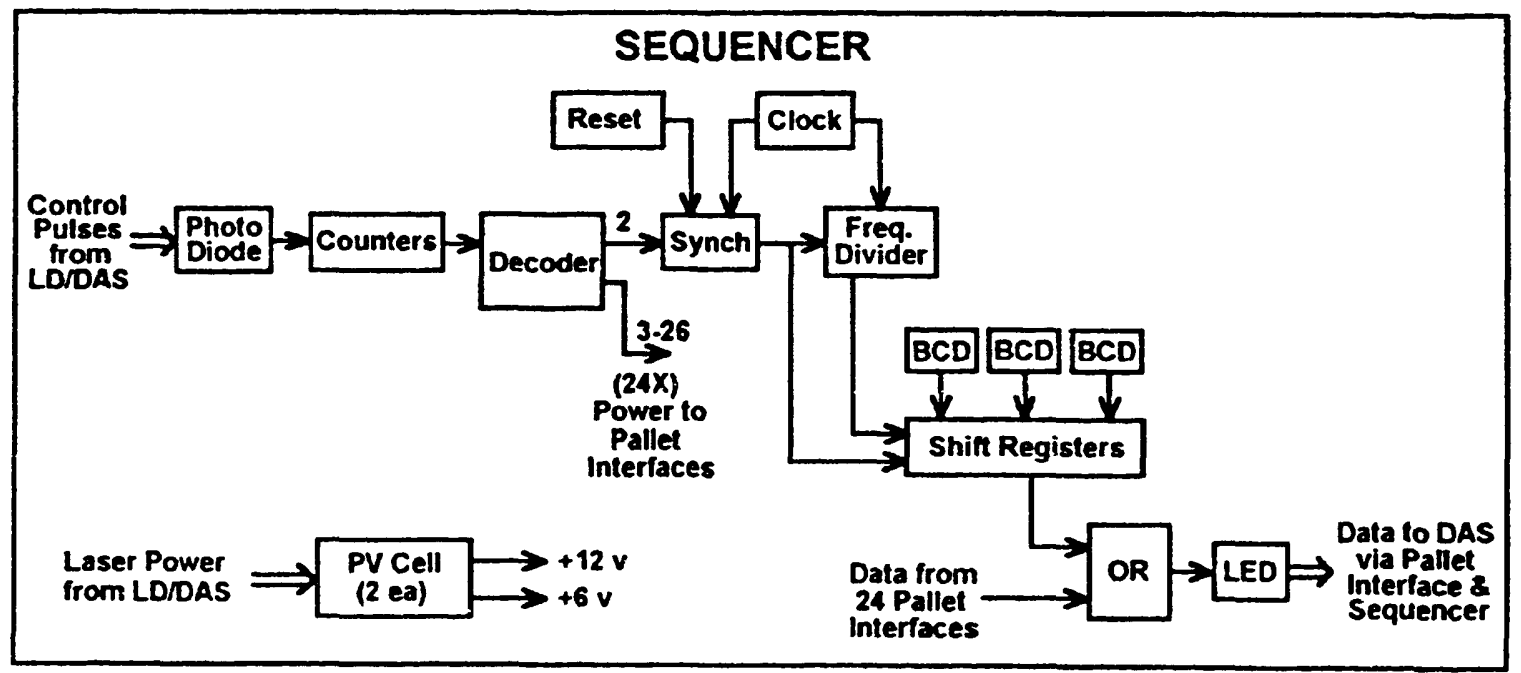

Figure 14. Sequencer Bock Diagram. 


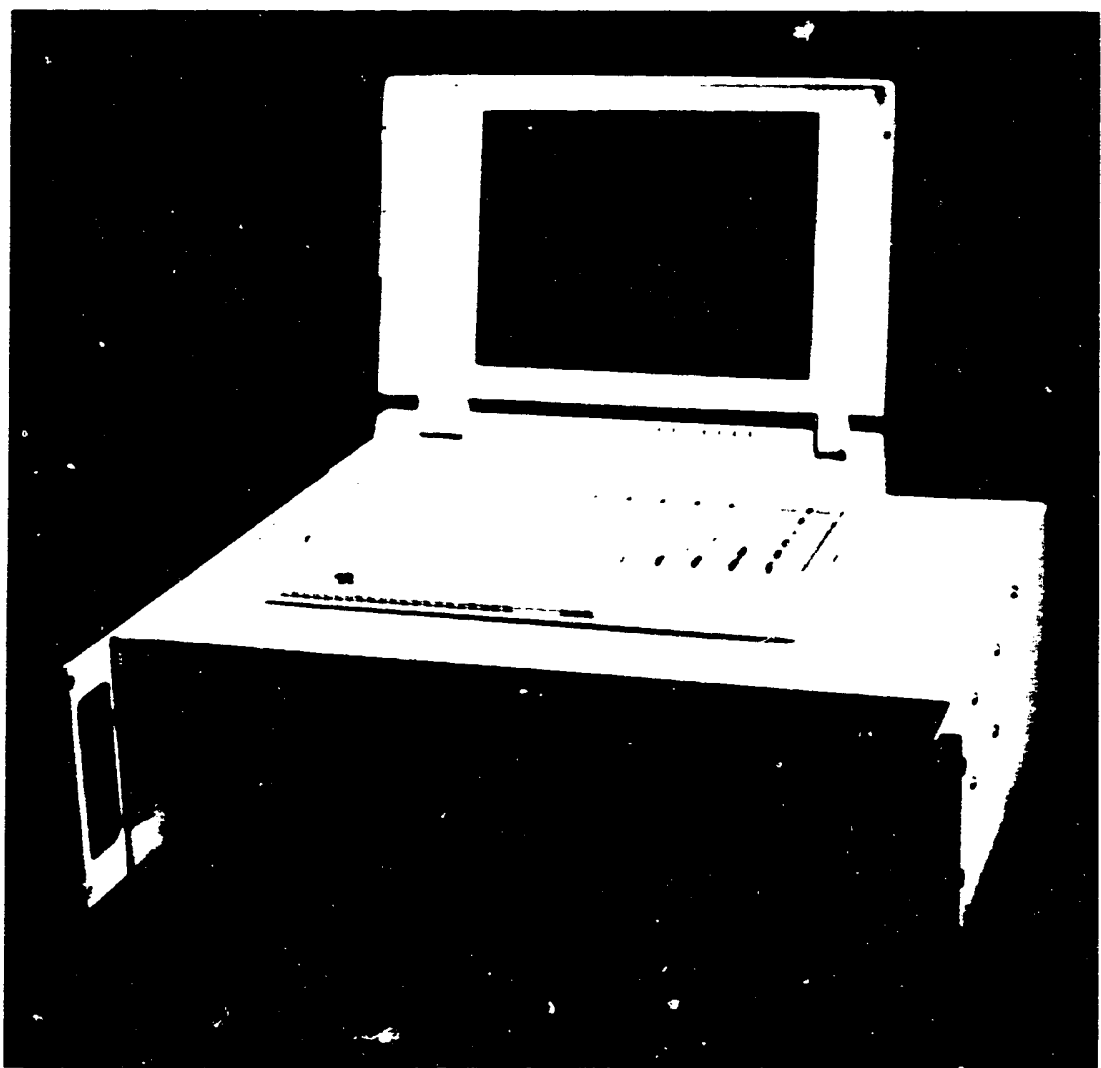

Figure 15. Prototype Laser Driver/Data Acquisition System.

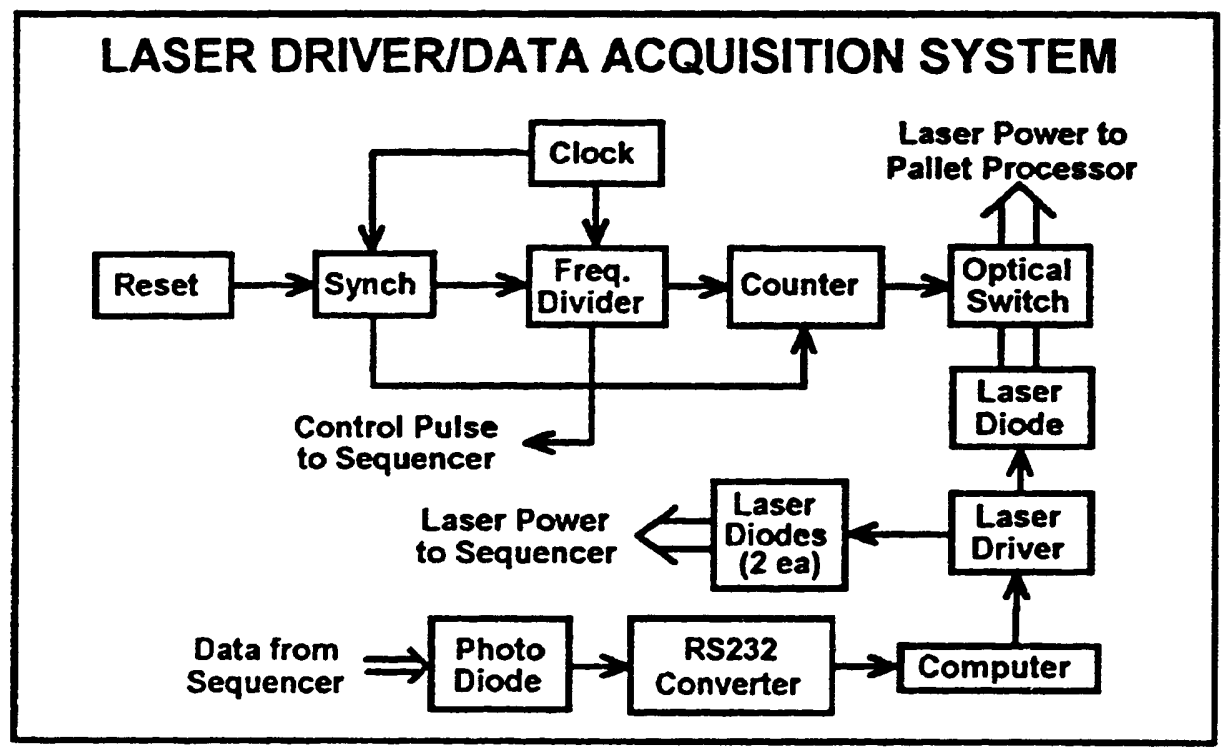

Figure 16. Laser Driver/Data Acquisition System Block Diagram. 


\section{Operational Scenario}

The OIS operation is best illustrated by presenting a typical inventory scenario. This scenario is only intended as an illustration and may vary drastically based on the actual operational requirements.

\section{Initial Data Acquisition.}

a. Pit from dismantled unit is placed in AL-R8 container.

b. Lid with LP attached is installed and secured on container.

c. LP is programmed with part and serial numbers of pit.

d. LD/DAS verifies data.

e. LP is sealed.

f. Data is reverified by LD/DAS and stored in data base.

g. Container is placed on pallet, and PP cable is connected to LP.

h. For subsequent pits, steps a through $g$ are repeated until pallet is full.

i. PP is connected to LD/DAS.

j. LP data is reverified and sent to data base along with pallet ID number.

k. Integrity of container security seals is verified.

\section{Pallet Loading}

a. Full pallet(s) is transported to magazine.

b. Concrete obstructions are removed from magazine access pad.

c. Magazine security systens are deactivated.

d. Pallet is rotated for loading.

e. Integrity $f$ container security seais is reverified.

f. Robotic vehicle places pallet in selected position in magazine.

g. Magazine doors are closed.

h. Fiber-optic cables from mobile LD/DAS are connected to FOI.

i. LD/DAS inventories magazine contents.

j. Cables are disconnected.

k. Magazine doors are secured.

1. Concrete obstructions are repositioned on magazine pad.

m. Magazine security systems are reactivated.

3. Periodic Inventory Operations.

a. Integrity of magazine security system is verified.

b. LD/DAS is connected to magazine FOI. c. Electronic inventory of magazine is performed.

d. Fiber-optic cable from LD/DAS is disconnected.

e. Integrity of magazine security system is reconfirmed.

f. Inventory operation is complete.

\section{Data Analys is and Reconciliation.}

Obtained inventory data is analyzed and reconciled with historical data:

a. No discrepancy - acceptable inventory

b. Discrepancy - appropriate course of action to be determined

The advantages of the OIS are obvious in the above scenario. Whiie the majority of the tasks listed for the initial data acquisition and pallet loading operations must be performed regard less of what ty pe of inventory system is used, the simplicity of operations for periodic inventory operations eliminates the need for magazine entry. This elimination results in enhanced operational safety and security, and because tne total elapsed time for inventory operations is drastically reduced, operational costs for inventory operations exhibit similar reductions. Finally, since the time to inventory one magazine can be measured in minutes rather than hours (if not days), inventory operations can be conducted "on demand" if desired.

\section{Development Status}

As of publication of this document, the OIS development program is incomplete. Because of program redirection, the environmental, life, and reliability testing phase of the development program could not be completed. For the same reason, the development team's goal of improving the system to accommodate \pm 1.5 inches of pallet misalignment and a 12-inch gap has not been realized. Although we believe the system will meet the program requirements, those requirements will only be confirmed if the program is reactivated so that tests and enhancements can be completed. Also, although the basic concepts for the installation have been generated and proto:y pe demonstration hardware fabricated, no formal engineering drawings detailing the installation, cables, circuit boards, etc., were completed. As a result, this document constitutes the extent of the formal documentation for the OIS. 


\section{Discussion}

Although the OIS system described in this document is tailored for the facilities and inventory requirements for nuclear materials staged at Pantex, the system is readily adaptable to similar applications. If the system is viewed as a basic concept rather than a spexific-use system, it is easy to see the dual-use possibilities for the OIS. Not only can the system be used to inventory pits; we can also invision similar installations for sensitive materials, precious metals, or hazardous materials. Any application requiring the retrieval of information from secured or limited-access facilities would benefit from the use of an optoelectronic system. The adaptability of the OIS concept may be its greatest asset:

- An OIS can be integrated into new construction or retrofitted into old as is the case with the
Mason \& Hanger Pantex application.

- The system can be sized to obtain information from tens, hundreds, or thousands of items from either permanent or mobile facilities.

- The OIS can interface with a wide range of miniature sensors (both optic and electronic), such as fiber-optic strain gauges, strain-optic voltage monitors, or microbend fiber-optic sensors for temperature or stain.

- Incorporation of encryption capabilities can also be foreseen should that capability be included in a system's requirements.

As with the system designed for Pantex, prefabrication and modularized construction techniques using mature and robust components can provide the user with a wide range of capabilities and design options. 
DISTRIBUTION:

\begin{tabular}{|c|c|c|c|c|c|}
\hline \multirow{2}{*}{\multicolumn{3}{|c|}{ H. T. Season, Jr. }} & 1 & MS0487 & J. D. Mangum, 5121 \\
\hline & & & 1 & MS0486 & W. D. Chadwick, 5!22 \\
\hline \multirow{2}{*}{\multicolumn{3}{|c|}{ Albuquerque, NM }} & 1 & MS0485 & M. E. Bleck, 5123 \\
\hline & & & 1 & MS9203 & E. T. Cull, 5354 \\
\hline \multirow{2}{*}{\multicolumn{3}{|c|}{$\begin{array}{l}\text { W. J. Baca } \\
\text { DOE/AL/WPD }\end{array}$}} & 1 & MS9203 & B. M. Mickelsen, 5354 \\
\hline & & & 1 & MS9013 & R. G. Miller, 5366 \\
\hline \multirow{2}{*}{\multicolumn{3}{|c|}{ Albuquerque, NM }} & 1 & MS9203 & K. L. Schroder, 5354 \\
\hline & & & 1 & MS0473 & H. J. Saxton, 5400 \\
\hline \multicolumn{3}{|c|}{ D. D. Monette } & 1 & MS1058 & P. A Longmire, 5407 \\
\hline \multirow{2}{*}{\multicolumn{3}{|c|}{$\begin{array}{l}\text { DOE/AL/WPD } \\
\text { Albuquerque, NM }\end{array}$}} & 1 & MS1058 & R. W. Martin, 5407 \\
\hline & 1 & MS0769 & D. S. Miyoshi, 5800 \\
\hline & & & 1 & MS0768 & J. W. Kane, 5806 \\
\hline \multicolumn{3}{|c|}{ D. Whitson } & 1 & MS0768 & C. L. Schuster, 5806 \\
\hline \multirow{2}{*}{\multicolumn{3}{|c|}{$\begin{array}{l}\text { M \& H Pantex } \\
\text { Amarillo, TX }\end{array}$}} & 1 & MS0765 & D. E. McGovern, 5821 \\
\hline & & & 1 & MS0782 & J. F. Chapek, 5848 \\
\hline 1 & MS0513 & H. W. Schmitt, 2000 & 1 & MS1322 & J. R. Tillerson, 6121 \\
\hline $\mathbf{1}$ & MS0322 & P. J. Eiker, 2100 & 1 & MS0752 & A R. Mahoney, 6213 \\
\hline 1 & MS1007 & w. D. Drotning, 2171 & 1 & MS0752 & L. P. Schanwald, 6219 \\
\hline 1 & MS1070 & R. E. Bsir, 2200 & 1 & MS0726 & J. B. Woodard, 6600 \\
\hline 1 & MS0521 & C. F. Gibbon, 2204 & 1 & MS0755 & A. E. Verardo, 6612 \\
\hline 1 & MS1071 & T. J. Allard, 2205 & 1 & MS0970 & I. A Sellers, 9200 \\
\hline 1 & MS0527 & K. R. Nielsen, 2231 & 1 & MS0567 & J. M. Taylor, 9241 \\
\hline 1 & MS0527 & E. P. Royer, 2231 & 1 & MS0656 & J. C. Matter, 9246 \\
\hline 10 & MS0527 & F. H. Sieradzki, 2231 & 1 & MS0431 & M. J. Eaton, 9400 \\
\hline 1 & MS0527 & T. A Fischer, 2235 & 1 & MS0777 & M. R. Sjulin, 9417 \\
\hline 1 & MS0985 & J. H. Stichman, 2600 & 1 & MS0766 & J. R. Kelsey, 9600 \\
\hline 1 & MS0987 & R. J. Longoria, 2611 & 1 & MS1125 & B. C. Caskey, 9616 \\
\hline 1 & MS0987 & J. H. Perry, 2611 & 1 & MS9018 & Central Technical Files, 8523-2 \\
\hline 1 & MS0987 & M. R. Stegmaier, 2611 & 5 & MS0899 & Technical Library, 7141 \\
\hline 1 & MS0471 & J. P. Abbin, 5093 & 1 & MS0619 & Technical Publications, 7151 \\
\hline 1 & MS0427 & W. R. Reynolds, 5103 & 10 & MS0100 & $\begin{array}{l}\text { Document Processing } \\
\text { For DOE/OST1, 7613-2 }\end{array}$ \\
\hline
\end{tabular}



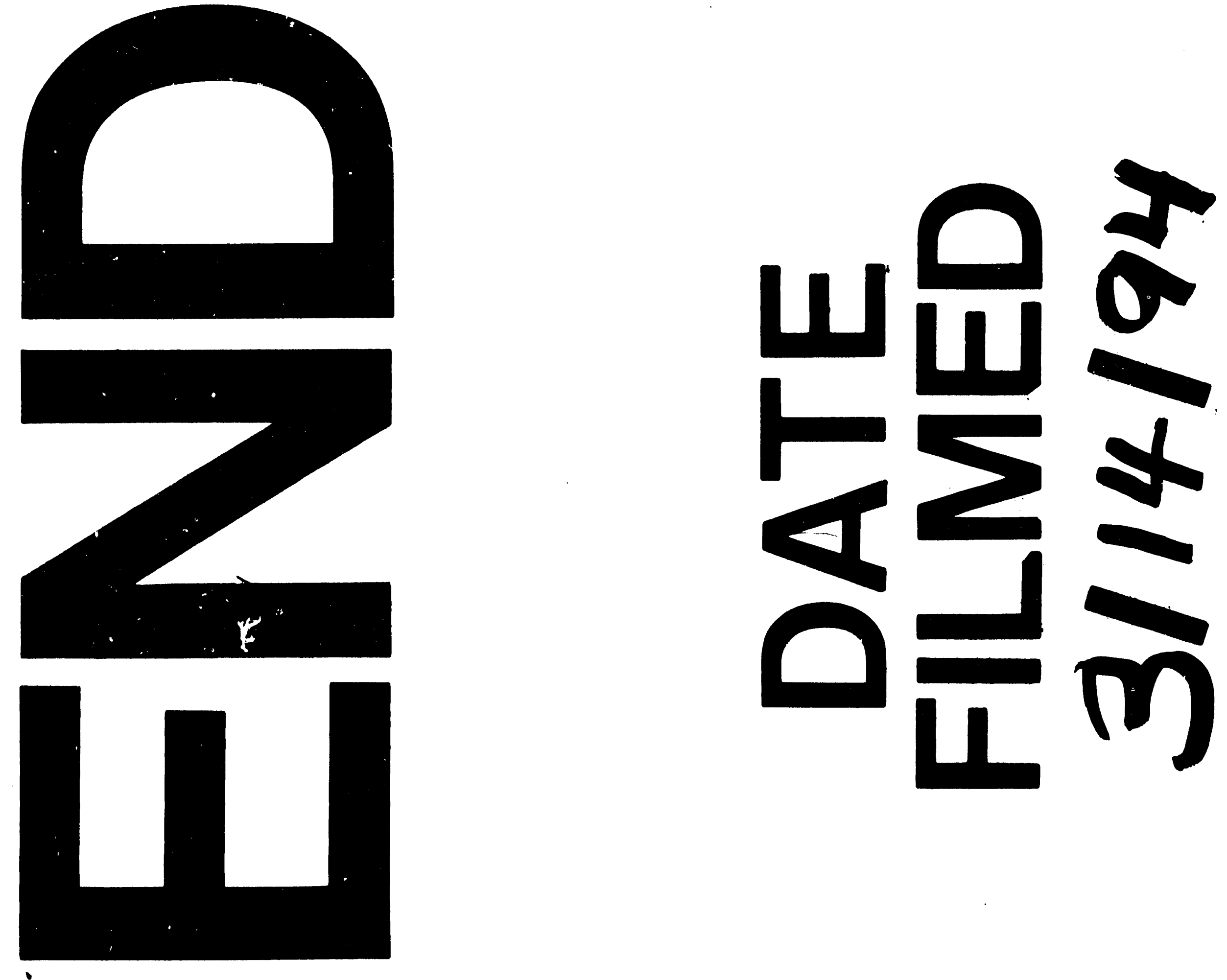

1

$\sim$ 